\title{
Near vision correction and work productivity among textile workers
}

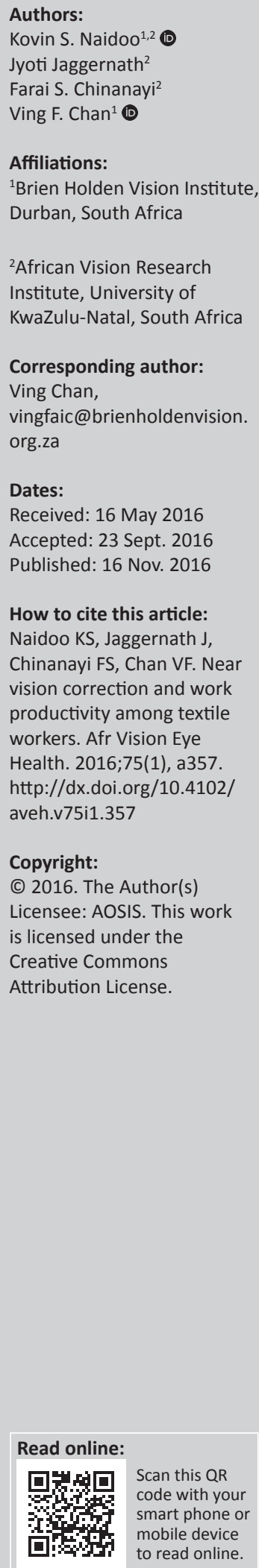

Purpose: Uncorrected presbyopia (near vision impairment) is prevalent in approximately 517 million people worldwide; this prevalence ranges from $30 \%$ to $80 \%$ in Africa. Good near vision is needed for a range of tasks; therefore, uncorrected presbyopia can negatively affect the quality of life of individuals, impact families and society, and potentially have negative implications on employment and labour work productivity. This study aimed to determine the impact of near vision correction on the work productivity of clothing factory workers.

Methods: We conducted a cross-sectional study and sampled all workers who were aged 40 years and older and who performed near vision tasks (e.g. machinist, cutter, zip sewer, clothing pressers and quality controllers) in seven clothing factories. We included workers who were employed for at least 3 months and whose uncorrected near visual acuity could be improved and corrected to better than $6 / 9$ with spectacle correction. Workers were provided with near vision spectacles, and changes in their work productivity were evaluated after 6 months, using the factories' output records as an indicator for measurement.

Results: The final sample comprised 268 individuals, with $56 \%$ of African origin $(n=151)$ and $49 \%(n=115)$ Indian origin. There were mainly females $(94 \%)$ in the sample, and the average age was 48 years ( \pm 5.5 years, range $40-62$ years). The overall post-correction mean production score $(70.5[\mathrm{SD} \pm 19.9])$ was significantly higher than the overall pre-correction mean production score $(67.0$ [SD \pm 20.3$])(p<0.001)$. The average change in production score was $3.5(95 \%$ confidence interval [CI] 2.7-4.3), and the percent difference was $6.4 \%$ (95\% CI 5.2-7.7). The increase in work productivity was significant for individuals of African $(p<0.001)$ and Indian origins $(p<0.001)$ but not for those of mixed race $(p=0.364 ; n=2)$. Post-correction, the production scores of women increased significantly by $6.6 \%(95 \%$ CI $5.3-7.9)(p<0.001)$. Significant increases in production scores were recorded for machinists, clothing pressers and quality controllers.

Conclusion: Significant changes in work productivity among the workers with presbyopic correction were recorded. The clothing industry served as a favourable setting to examine changes in work productivity, obtaining reliable scores of output. This study was used as an exploratory investigation, and the results will be used to inform a randomised-controlled study that will provide stronger validation for the hypothesis that near vision correction impacts work productivity.

\section{Introduction}

Presbyopia is an age-related condition wherein the ability of the lens to focus on near objects becomes progressively difficult, particularly affecting individuals aged 40 years and older. ${ }^{1}$ The condition is the most common physiological change occurring in the adult eye causing universal near vision impairment with advancing age. ${ }^{2}$ Estimates from a 2008 survey indicated that 517 million people in the world have uncorrected presbyopia (near vision impairment), and this prevalence ranges from $30 \%$ to $80 \%$ in Africa. $^{3}$

Good near vision is needed for tasks other than reading and writing, ${ }^{2}$ such as sewing, cooking, farming and caring for families. The onset of presbyopia is gradual; the patient's accommodative amplitude slowly becomes inadequate for his or her visual needs. ${ }^{4}$ The lens is connected by fibres (zonules) to the ciliary body of the eye. These zonules are relaxed by contraction of the circular fibres of the ciliary muscles, permitting the lens to widen (increase in size in its anterior-posterior diameter) and focus more clearly on near objects. Presbyopia occurs when there is a decrease in the ability of the lens to change shape and to focus clearly on near vision objects as the circular fibres of the ciliary muscle weaken. Variability in the onset and degree of presbyopia can depend on climate, geographic location, sex, ethnicity and visual requirements. ${ }^{5}$ 
The simplest and most cost-effective method of correcting presbyopia is through spectacle correction. Despite this, many people (as high as 95\%) with uncorrected presbyopia do not have access to a pair of affordable reading spectacles, mainly as a result of limited access to primary eye care services. ${ }^{3}$ Uncorrected presbyopia affects the quality of life of individuals, their family and society, and can have negative implications towards their employment. ${ }^{6}$ These negative implications may also include dissatisfaction with their ability to perform tasks that require the use of near vision such as cooking, sewing and weeding. ${ }^{2}$ The estimated global economic productivity loss due to uncorrected presbyopia is $\$ 202 \mathrm{bn} .^{7}$

Failing to provide for the vision health needs of their citizens, many countries may experience detrimental effects on labour productivity. Anecdotal evidence has suggested that uncorrected near refractive error can decrease work productivity. Stemming from the limited published evidence on spectacle correction and worker productivity, this preand post-intervention study over a 6-month period intends to investigate increases in the work productivity of textile factory workers following an eye assessment and near vision spectacle correction.

\section{Methods}

\section{Study sample}

The study included 268 textile workers from seven clothing factories in KwaZulu-Natal, South Africa (see Table 1). The clothing sector is well established, with three levels of manufacturers; many are operational and handle cutting, making and trimming. Other participant manufacturers are design houses and independent retailers who specialise in pre-production and distribution. As textile manufacturing includes a number of skills, we selected only factories which involve quantifiable near vision tasks, such as using a machine for sewing, cutting fabrics, making buttonholes and sewing on buttons and zips.

In this explorative study, we employed an exhaustive sample of all textile factory employees who were 40 years of age and older (mean $48 \pm 5.5$ years of age), and who performed tasks of a machinist, cutter, zip sewer and others (ironing and quality control) in the seven textile factories. We only included textile factory workers who have worked at least 3 months in the factory. We further divided the participants into different groups, such as gender, ethnicities, education and responsibilities while performing analyses.

The operational definition of 'presbyopia' in this study was those whose near visual acuity (VA) can be improved to at least 6/9 equivalent at near and who were not currently wearing near vision spectacles with corrected VA better than $6 / 9$. Participants with reduced vision caused by other eye conditions were excluded from the study and referred to the nearest eye care facility for management.

\section{Clinical examination}

We gave all participants an ocular assessment, which included a comprehensive case history, distance and near VA testing, objective and subjective refraction, colour vision and ocular health examination. Distance VA was tested using a LogMAR chart at $4 \mathrm{~m}$, whereas near VA was tested using a near LogMAR chart at $40 \mathrm{~cm}$. Each participant was given objective and subjective refractions to determine their near refractive status. All participants who were identified as

TABLE 1: Mean production scores in Phases 1 and 2 and changes in production scores with correction for presbyopia.

\begin{tabular}{|c|c|c|c|c|c|c|c|c|c|c|c|}
\hline \multirow[t]{2}{*}{ Demographic profile } & \multirow[t]{2}{*}{$n$} & \multirow[t]{2}{*}{$\%$} & \multicolumn{2}{|c|}{$\begin{array}{l}\text { Phase } 1 \text { production } \\
\text { scores }\end{array}$} & \multicolumn{2}{|c|}{$\begin{array}{l}\text { Phase } 2 \text { production } \\
\text { scores }\end{array}$} & \multicolumn{2}{|c|}{$\begin{array}{l}\text { Change, production } \\
\text { score, mean }\end{array}$} & \multicolumn{2}{|c|}{ Change } & \multirow[t]{2}{*}{ Significance } \\
\hline & & & Mean & s.d. & Mean & s.d. & Mean & $95 \% \mathrm{Cl}$ & $\%$ & $95 \% \mathrm{Cl}$ & \\
\hline \multicolumn{12}{|l|}{ Ethnicity } \\
\hline African origin & 151 & 56.3 & 66.9 & 23.6 & 71.1 & 23.0 & 4.2 & $3.2-5.2$ & 7.8 & $6.2-9.4$ & $p<0.001$ \\
\hline Mixed race & 2 & 0.8 & 64.5 & 10.6 & 67.0 & 2.8 & 2.5 & $-67.4-72.4$ & 4.9 & $-110.7-120.6$ & $p=0.364$ \\
\hline Indian & 115 & 42.9 & 67.1 & 15.1 & 69.8 & 15.2 & 2.7 & $1.4-3.9$ & 4.6 & $2.7-6.6$ & $p<0.001$ \\
\hline \multicolumn{12}{|l|}{ Gender } \\
\hline Male & 16 & 6.0 & 74.8 & 19.0 & 77.1 & 20.2 & 2.4 & $-0.3-5.0$ & 3.1 & $-0.3-6.6$ & $p=0.074$ \\
\hline Female & 252 & 94.0 & 66.5 & 20.3 & 70.1 & 19.8 & 3.6 & $2.8-4.4$ & 6.6 & $5.3-7.9$ & $p<0.001$ \\
\hline \multicolumn{12}{|l|}{ Education } \\
\hline No formal schooling & 2 & 0.8 & 45.0 & 7.1 & 52.0 & 7.1 & 7.0 & - & 15.8 & $-6.5-38.0$ & - \\
\hline Primary school incomplete & 52 & 19.4 & 69.3 & 28.6 & 74.6 & 28.4 & 5.3 & $4.0-6.6$ & 9.3 & $7.1-11.5$ & $p<0.001$ \\
\hline Primary school complete & 18 & 6.7 & 57.3 & 14.7 & 63.2 & 14.0 & 5.8 & $3.6-8.1$ & 11.1 & $7.3-14.9$ & $p<0.001$ \\
\hline Secondary school incomplete & 151 & 56.3 & 67.7 & 18.5 & 70.2 & 17.7 & 2.5 & $1.3-3.6$ & 4.7 & $3.0-6.4$ & $p<0.001$ \\
\hline Skill learn on job or vocational & 1 & 0.4 & 67.0 & - & 82.0 & - & 15.0 & - & 22.4 & - & - \\
\hline Not stated & 1 & 0.4 & 61.0 & - & 60.0 & - & -1.0 & - & -1.6 & - & - \\
\hline \multicolumn{12}{|l|}{ Responsibility } \\
\hline Cutter & 2 & 0.8 & 46.5 & 16.3 & 50.0 & 11.3 & 3.5 & $-41.0-48.0$ & 10.0 & $-117.1-137.1$ & $p=0.250$ \\
\hline Machinist & 207 & 77.2 & 65.0 & 16.7 & 68.5 & 15.9 & 3.5 & $2.6-4.5$ & 6.6 & $5.1-8.0$ & $p<0.001$ \\
\hline Button or zip tailor & 1 & 0.4 & 61.0 & - & 60.0 & - & -1.0 & - & -1.6 & - & - \\
\hline $\begin{array}{l}\text { Others (Iron and quality } \\
\text { assurance) }\end{array}$ & 58 & 21.6 & 74.9 & 28.7 & 78.5 & 29.0 & 3.7 & $2.0-5.3$ & 5.8 & $3.3-8.3$ & $p<0.001$ \\
\hline
\end{tabular}

$\mathrm{Cl}$, confidence interval; s.d., standard deviation. 
being near vision impaired or presbyopic were given a full refraction, and corrective spectacles were supplied. All corrections were specifically for near vision in the form of single vision near spectacles. Any factory workers with an eye condition which may have affected their near vision, other than presbyopia, were referred for further management and excluded from the study.

\section{Outcome measures}

Before the implementation of the study, we obtained 3-month work productivity scores of each participant from the factory managers. A follow-up study was conducted 6 months after the initial visit. In the interim, regular telephonic reminders were conducted to remind the participants on the need to wear their correction (spectacles) during work and when conducting their work tasks. During follow-up, the participants' 6-month work productivity scores were collected from the factory managers.

Ergonomic factors were noted and considered in the initial visit to the seven textile factories before conducting the clinical eye examination and follow-up study. The visual demand of such tasks requires the consideration of a very large target size that enables the worker to perform the task comfortably and efficiently without having to strain his or her vision; sufficient viewing time to recognise details that are difficult to see at a glance; and adequate and consistent lighting which ensures a comfortable environment for any employee, irrespective of the work task or characteristic.

\section{Data analysis}

Outliers were considered to be values lower than or greater than 1.5 times the inter-quartile range (IQR). The IQR is the difference between the 75th and 25th percentiles. Comparisons between the baseline and follow-up data sets were conducted using the paired $t$-test because each individual had a baseline production score and a follow-up production score. The results were tested at a $5 \%$ level of significance.

The work productivity score was defined per individual as the amount of production in kilogrammes $(\mathrm{kg})$, which passed quality assurance per day. Percentage change in work productivity was calculated as follows:

100(Work productivity after correction, $\mathrm{kg}$ - Work

productivity before correction, $\mathrm{kg}$ )

Work productivity before correction, $\mathrm{kg}$

[Eqn 1]

'Passed quality assurance' refers to jobs that passed the quality check by line supervisors.

\section{Ethical considerations}

The research protocol was reviewed and approved by the Biomedical Research Ethics Committee (BREC), University of KwaZulu-Natal, South Africa. A copy of the information document was given to the participants, and informed consent was sought after explaining the aims and potential risks of the study. Participants also reserved the right to withdraw from the study at any point during the study.

\section{Results}

In Phase 1, there were 290 participants who were included in the study, and we were able to follow-up with 268 participants in Phase 2 (response rate $=92.4 \%$ ). The loss of follow-up was because of transfer to other tasks or departments, making the change in productivity scores impossible for comparison. Participants who had their productivity scores recorded in Phases 1 and 2 were the only ones included in this study to remove bias introduced by non-participants in either Phase 1 or Phase 2. Therefore, a total of 268 participants had their production scores reported in both phases. Productivity scores were reported by categorising them according to demography and responsibility at work.

Overall, outliers were observed in Phase 1 and Phase 2 productivity scores and differences between Phases 1 and 2 productivity scores. These were investigated and kept in the analysis as they were expected values from participants with different responsibilities except for where the percentage difference was more than or less than 1.5 times the IQR. In total, 22 participants had values between the intervals (from $-47.4 \%$ to $-23.1 \%)$ and $(38.3 \%-350.0 \%)$, and these were found to be outliers and removed from the analysis. We omitted the 22 participants to allow further analysis.

The overall production mean score for Phase 2 (70.5 [ \pm 19.9 $\mathrm{SD}])$ was significantly higher than the overall production mean score for Phase $1(67.0[ \pm 20.3])(p<0.001)$. The average change in production scores was 3.5 (2.7-4.3), and the percent difference was $6.4 \%(5.2-7.7)$.

There was an increase for the three ethnic groups included in the study; however, the increase was significant for the participants of African and Indian ( $p<0.001$, respectively) communities except the mixed race $(p=0.364)$. Perhaps, the latter was insignificant because of the number of participants where there were only two participants. Production scores between phases increased by $7.8 \%(6.2 \%-9.4 \%)$ for the black participants (see Table 1).

Females significantly increased their production between Phase 1 and Phase 2 by 3.6 (2.8-4.4) translating to $6.6 \%$ $(5.3 \%-7.9 \%)(p<0.001)$. On the other hand, there was an increase of $2.4(-0.3-5.0)$ translating to $3.1 \%(-0.3-6.6)$ for males even though it was not significant $(p=0.074$, see Table 1). Most of the educational categories had a significant increase in production scores except for no formal schooling and vocational training. The groups had only two participants and one participant, respectively. The highest significant increase by the level of education was 5.8 (3.6-8.1), which is $11.1 \%(7.3 \%-14.9 \%)(p<0.001)$ for those who completed primary school (see Table 1$)$. 
Machinists and those who have other responsibilities (ironing and quality assurance) had a significant increase in production scores by $6.6 \%(5.1 \%-8.0 \%)(p<0.001)$ and $5.8 \%$ $(3.3 \%-8.3 \%)(p<0.001)$, respectively (see Table 1$)$.

\section{Discussion}

The results indicate an improvement in work productivity with near vision spectacle correction. The overall percentage increase $(6.4 \%)$ can be significant in factories with high manufacturing production as this can translate into significant changes. Further, it has been stated that the world economy loses about \$202bn dollars per annum in lost productivity because of vision impairment. ${ }^{7}$ Furthermore, Frick et al. estimated that the potential productivity loss because of uncorrected presbyopia among people aged $<65$ years is about $\$ 25.367$ bn or $0.037 \%$ of the global GDP. ${ }^{7}$ In such a context, the change in productivity can translate to significant savings if such benefits translate across industries. Unfortunately, the lack of studies examining work productivity limits our ability to determine the extent of the impact.

There was no significant differences in work productivity gain between males and females even though the female to male ratio of 16:1 may have skewed the results. However, it should be noted that the clothing industry has a dominance of women and men represented only $6 \%$ of the total sample, and this would have impacted the results. Some studies assessing health risk and work productivity could not find conclusive results in work productivity gain between men and women. ${ }^{8,9}$

The difference in significance of the productivity gain among those conducting various tasks (including the gain not being significant for cutters) raises questions about the relevance of near vision tasks as opposed to particular near vision tasks. The cutters need good vision as their work is predominantly at near as compared to the other tasks but may vary in the level of detail involved. It will therefore be useful to investigate the productivity gain between various near tasks within a particular industry rather than grouping them as we have done.

Our study was an explorative one, and as such the study design limits some of the conclusions. It would have been ideal to include a randomised control study design which would have ruled out any other factors influencing the outcomes of this study. The investigators are currently planning such a study, and the data from this study will inform the approach.

The lack of studies regarding productivity loss because of near vision impairment restricts the capacity to influence investment in eye care services by industry as many companies may not appreciate the financial benefits of doing so. Investments in such studies are needed to ensure the success of future advocacy efforts as they will be supported by effective data.

\section{Acknowledgements Competing interests}

The authors declare that they have no financial or personal relationships which may have inappropriately influenced them in writing this article.

\section{Authors' contributions}

K.S.N. was the principal investigator of the study. He was involved in the design of the study, which included writing up the proposal, designing the tool and data analysis. He contributed to the overall write-up of the manuscript. J.J. was the co-investigator of the study. She was involved in the design of the study, which included writing up the proposal, designing the tool and data collection. She contributed $20 \%$ to the write-up of the study. F.S.C. was the statistician and co-investigator of the study. He was involved in the design of the study, focusing on sample size calculation, data management and data analysis. He contributed $20 \%$ to the write-up of the study. V.F.C. was the co-investigator of the study. He was involved in the design of the study, focusing on the writing up of the proposal, designing of the tool and implementation, data management and data analysis of the study. He contributed $60 \%$ to the write-up of the study.

\section{References}

1. Apparatus and processes for preventing or delaying one or more symptoms of presbyopia. 2007 [cited 2015 Mar 20]. Available from: https://www.google.com/ patents/US7252662

2. Patel I, Munoz B, Burke AG, et al. Impact of presbyopia on quality of life in a rural African setting. Ophthalmology. 2006;113(5):728-734. http://dx.doi.org/10.1016/j. ophtha.2006.01.028

3. Holden BA, Fricke TR, Ho SM, et al. Global vision impairment due to uncorrected presbyopia. Arch Ophthalmol. 2008;126(12):1731-1739. http://dx.doi.org/10. 1001/archopht.126.12.1731

4. Khalaj M, Gasemi H, Barikani A, Ebrahimi M, Rastak S. Prevalence of presbyopia among smoking population. J Eye Ophthalmol. 2014;1(1):1.

5. Laviers HR, Omar F, Jecha H, Kassim G, Gilbert C. Presbyopic spectacle coverage, willingness to pay for near correction, and the impact of correcting uncorrected presbyopia in adults in Zanzibar, East Africa. Invest Ophthalmol Vis Sci. 2010;51(2):1234-1241. http://dx.doi.org/10.1167/iovs.08-3154

6. Holden BA. Uncorrected refractive error: The major and most easily avoidable cause of vision loss. Community Eye Health. 2007;20(63):37-39.

7. Frick KD, Joy SM, Wilson DA, Naidoo KS, Holden BA. The global burden of potential productivity loss from uncorrected presbyopia. Ophthalmology. 2015;122(8): 1706-1710.

8. Dean BB, Crawley JA, Schmitt CM, Wong J, Ofman JJ. The burden of illness of gastro-oesophageal reflux disease: Impact on work productivity. Aliment
Pharmacol Ther. 2003;17(10):1309-1317. http://dx.doi.org/10.1046/j.1365-2036. 2003.01588.x

9. Tunceli K, Bradley CJ, Nerenz D, Williams LK, Pladevall M, Elston Lafata J. The impact of diabetes on employment and work productivity. Diabetes Care. 2005;28(11):2662-2667. http://dx.doi.org/10.2337/diacare.28.11.2662 